Research Article

\title{
Vibration in a Multistage Centrifugal Pump under Varied Conditions
}

\author{
Ling Bai, ${ }^{1}$ Ling Zhou $\mathbb{D},{ }^{1}$ Xiaoping Jiang $\mathbb{D},{ }^{2}$ Qinglong Pang, ${ }^{1}$ and Daoxing Ye $\mathbb{D}^{3}$ \\ ${ }^{1}$ National Research Center of Pumps, Jiangsu University, Zhenjiang 212013, China \\ ${ }^{2}$ National Engineering and Technology Center for Information Agriculture, Nanjing 210095, China \\ ${ }^{3}$ Key Laboratory of Fluid and Power Machinery, Ministry of Education, Xihua University, Chengdu 610039, China \\ Correspondence should be addressed to Ling Zhou; lingzhoo@hotmail.com and Xiaoping Jiang; jxp2502@163.com
}

Received 23 February 2019; Revised 13 May 2019; Accepted 22 May 2019; Published 11 June 2019

Academic Editor: Angelo Marcelo Tusset

Copyright (c) 2019 Ling Bai et al. This is an open access article distributed under the Creative Commons Attribution License, which permits unrestricted use, distribution, and reproduction in any medium, provided the original work is properly cited.

\begin{abstract}
Multistage pumps are intended to improve designs with low-vibration and -noise features as the industry applications increase the technical requirements. In this frame, it becomes really important to fully understand the vibration patterns of these kinds of complex machines. In this study, a vibration test bench was established to examine the vibration and stability of a cantilever multistage centrifugal pump under different flow rates. The vibration spectrum diagrams for the inlet and outlet sections and the pump body were evaluated under varied flow conditions. Results showed the effects of operational conditions on the vibration of the cantilever multistage centrifugal pump. Vibration velocity was primarily caused by mass unbalance at the shut-off flow rate point. Under different flow conditions, the blade passing frequency (BPF) and two times the blade passing frequency (2BPF) were the main excitation frequencies. The vibration frequency of the final pump body remained at the BPF under different flow conditions due to the contact with the outlet section. The major type of vibration frequency for the inlet and outlet was high frequency.
\end{abstract}

\section{Introduction}

As an important device used for energy conversion and fluid transportation, multistage centrifugal pumps are widely used in agriculture and industry [1-3]. Examples are cantilever multistage pumps, which have the features of good maintainability and simple structure. In some applications, high requirements are set for the vibration and noise of multistage pumps. Numerous industries are relying not only on the operation of pumping systems with different required operating flow rates but also on the design flow rate. Thus, studying the general patterns and collecting the database of vibration in multistage pumps under varied flow conditions are important.

Vibration of pumps is complex, and structural characteristics, rotor unbalance, and unsteady fluid force can increase the possibility of generating nonlinear gyroscopic moment [4-6]. Moreover, dynamic faults, rotor instability, and airframe vibration increase during operation $[7,8]$.
Addressing these problems are current targets of research efforts to facilitate improved and increased application [9]. Numerous studies have been conducted to examine vibration patterns by experimental and numerical methods. Khalifa [10] considered the effect of the shape of the blade outlet on pump vibration by testing the effects of V-, C-, and straight-cut-shaped blade outlets. Grosel et al. [11] applied different methods of data acquisition, tested pump vibration through a multichannel pulse system, and concluded that operational modal analysis could provide reasonable results. Yang et al. [12] adopted experimental and numerical approaches to study the unsteady flow characteristics and instability in the first stage of a multistage pump turbine in the pump mode. Al Tobi et al. [13] used vibration analysis and automatic diagnostic methods to analyze the vibration patterns in a centrifugal pump. Muralidharan et al. [14] investigated a centrifugal pump with a constant speed, an accelerometer sensor was mounted on the pump suction, and signals were processed at a sampling rate of $24 \mathrm{kHz}$ and a 
sample length of 1024. The aforementioned studies are mostly limited to single-stage centrifugal pumps, and reports on vibration in a multistage centrifugal pump, especially a cantilever multistage centrifugal pump, are unavailable.

In this study, a cantilever multistage centrifugal pump was selected as a research model to evaluate vibration patterns under varied flow conditions. The vibrations in the inlet and outlet sections and pump body of the model pump were monitored using a Bently ADRE 408 portable vibration tester. The vibration characteristics of each monitoring point were analyzed by fast Fourier transform (FFT) and spectrum analysis under shut-off, part-loading, design, and overloading flow conditions. The results could extend the database to optimize the design of multistage pumps.

\section{Test Rig}

2.1. Pump Parameters. The major design parameters of the cantilever multistage centrifugal pump are presented in Figure 1, with a flow of $Q_{\text {des }}=4.8 \mathrm{~m}^{3} / \mathrm{s}$, four stages, singlestage head of $H_{\mathrm{s}}=8 \mathrm{~m}$, motor rotation speed of $n=2800 \mathrm{r} / \mathrm{min}$, number of impeller blades of $z_{\mathrm{i}}=8$, and number of diffuser vanes of $z_{\mathrm{d}}=12$. The diffuser vanes were located at the downstream of impeller blades.

2.2. Test Device. As shown in Figure 2, a vibration test system was designed and established for a cantilever multistage pump test in the laboratory of National Research Center of Pumps, China. The vibration test system comprised an ADRE 408 vibration fault test system, a cantilever multistage centrifugal pump, and a closed-type test bench. This vibration fault test system included a portable dynamic data tester, a 16-channel data acquisition card, and corresponding sensors. The system software could conduct timeand frequency-domain analyses and perform multiple operations for signals, such as integration, filtering, and adding additional monitor window. The sensitivity coefficient was set to $100 \mathrm{mV} / \mathrm{g}$ after vibration monitoring by the acceleration composite probe sensor.

2.3. Sensor Installation and Sampling. The inlet pipe, inlet and outlet cavities, and first, second, third, and final stages were selected as the monitoring points to meet the research objectives and assess the structural characteristics of the cantilever multistage centrifugal pump. Vibration sensors were installed at these positions to acquire vibration data. The installation of sensors at each vibration monitoring point is shown in Figure 3 and Table 1, with the initial phase of probes at the 0 -time direction set to $0^{\circ}$. Vibration velocity could be used to represent the vibration intensity, given the cantilever centrifugal pump is a type of rotating equipment. The vibration frequency range was set to $0-5,000 \mathrm{~Hz}$. The sampling frequency was $12,800 \mathrm{~Hz}$ with a recording time of $100 \mathrm{~ms}$.

2.4. Analysis Method of Vibration Signals. Vibration signals contain abundant state information, such as amplitude,

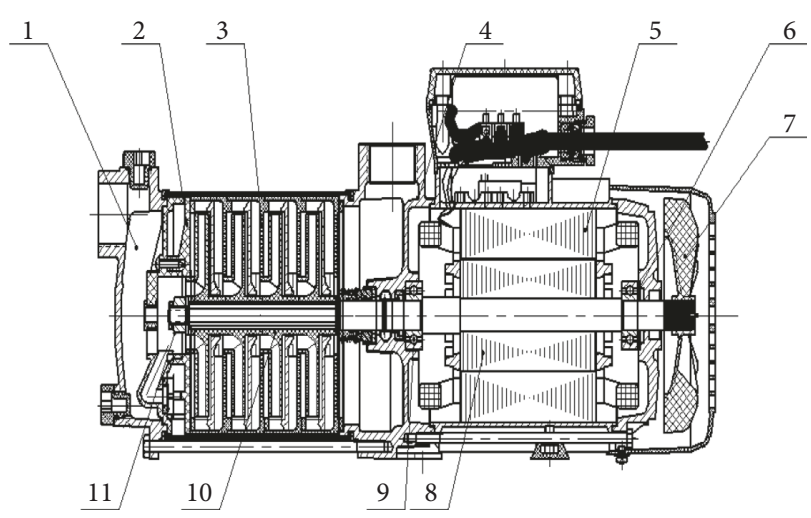

FIgURe 1: Assembly diagram of the cantilever multistage pump. 1, inlet cavity; 2 , self-priming cavity; 3 , diffuser vane; 4 , outlet cavity; 5 , motor stator; 6 , right end bearing; 7 , fan; 8 , motor rotor; 9 , left end bearing; 10, impeller; 11 , fastening screw.

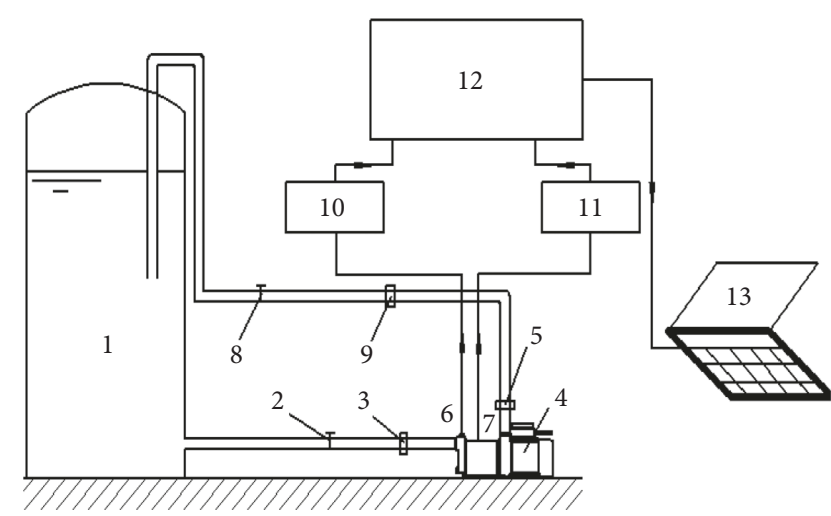

Figure 2: Test system and data acquisition. 1, regulator tank; 2, valve; 3 , inlet pressure gauge; 4 , pump; 5 , outlet pressure gauge; 6 , displacement sensor; 7, acceleration sensor; 8, outlet valve; 9, electromagnetic flow meter; 10 , acquisition card A; 11, acquisition card B; 12, Bently tester; 13, computer.

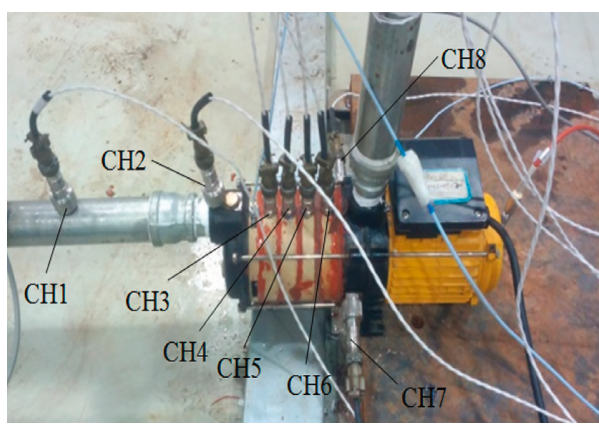

FIGURE 3: Installation of vibration sensors.

vibration frequency, phase, and all state parameters of rotating machines. According to studies on vibration in rotating machineries [15], amplitude is an important index of vibration, and the vibration state of a centrifugal pump can be directly determined by monitoring the amplitude. Although the nature of vibration will not change with the signal pattern, the vibration characteristics may vary. The 
TABle 1: Position of each monitoring point.

\begin{tabular}{lc}
\hline Channel number & Position \\
\hline $\mathrm{CH} 1$ & Pump inlet pipe \\
$\mathrm{CH} 2$ & Inlet of the first-stage impeller \\
$\mathrm{CH} 3$ & Outlet of the first-stage impeller outlet \\
$\mathrm{CH} 4$ & Outlet of the second-stage impeller outlet \\
$\mathrm{CH} 5$ & Outlet of the third-stage impeller outlet \\
$\mathrm{CH} 6$ & Outlet of the fourth-stage impeller outlet \\
$\mathrm{CH} 7$ & Pump outlet cavity \\
$\mathrm{CH} 8$ & Pump outlet pipe \\
\hline
\end{tabular}

vibration velocity amplitude is the product of the vibration displacement amplitude and the frequency, and the vibration acceleration amplitude is the product of the vibration displacement and the square of the frequency $[16,17]$. Both amplitudes reflect the influences of the vibration displacement and the frequency simultaneously. In this study, velocity signals were sampled and obtained after integral operation using acceleration sensors by considering the wide vibration frequency range of the model pump. The vibration spectrum of the signals was then obtained by FFT.

The shaft frequency $f_{\mathrm{s}}$ was calculated on the basis of motor rotation speed (i.e., $f_{s}=n / 60=2800 / 60=46.67 \mathrm{~Hz}$ ). The blade passing frequency (BPF) $f_{\mathrm{bp}}$ is the harmonics of shaft frequency $f_{\mathrm{s}}$, which can be calculated through the impeller blade number $z_{1}$, as $f_{\mathrm{bp}}=z_{1}$ and $f_{\mathrm{s}}=373.3 \mathrm{~Hz}$.

\section{Test Results and Analysis}

The pump operating flow conditions could be controlled and changed accordingly by adjusting the valve on the outlet pipe. Tests were performed under different flow conditions, including the shut-off flow rate point $\left(0 Q_{\text {des }}\right)$, design flow rate point $\left(1.0 Q_{\text {des }}\right)$, and overloading flow rate point $\left(1.5 Q_{\text {des }}\right)$. The vibration spectra were analyzed to assess the vibration state of the pump $[18,19]$.

\subsection{Vibration Spectrum Analysis for Inlet and Outlet Sections.} The vibration spectra were measured at two monitoring points (i.e., the inlet pipe $(\mathrm{CH} 1)$ and inlet cavity $(\mathrm{CH} 2))$ for five flow conditions (i.e., $0 Q_{\text {des }}, 0.6 Q_{\text {des }}, 1.0 Q_{\text {des }}, 1.25 Q_{\text {des }}$, and $1.5 Q_{\text {des }}$ ), as shown in Figure 4. The vibration spectrum at the inlet pipe of $\mathrm{CH} 1$ is shown in Figure 4(a). At the shut-off point, the vibration velocity amplitude increased to 4-6.5 times of the BPF, with a maximum amplitude of $0.94 \mathrm{~mm} / \mathrm{s}$. At the design flow rate, the amplitude of the vibration velocity decreased compared with the part-loading conditions; however, the vibrations remained within the range of $0-2,4-8$, and $11-12$ times of the BPF, which indicated that the harmonics of BPF exerted important effects on the vibration. Under overload flow conditions, the amplitude was reduced to the minimum value, and the vibration velocity reached $0.59 \mathrm{~mm} / \mathrm{s}$.

The vibration spectrum of $\mathrm{CH} 2$ at the pump inlet cover was determined, as shown in Figure 4(b). Under the flow rate of $0 Q_{\text {des }}$, obvious vibration occurred and concentrated within the 8-9 times BPF range, with the highest amplitude of $2.21 \mathrm{~mm} / \mathrm{s}$. Under the design flow rate, the amplitude of vibration velocity was reduced overall. The vibration remained obvious within the ranges of $0-2$ and 6-10 times the BPF, with the maximum up to $0.73 \mathrm{~mm} / \mathrm{s}$. Under a high flow rate, the amplitude of the vibration velocity was reduced to a great extent. The vibration mainly appeared at the range of 0-2 and 6-8 times the BPF, and the maximum amplitude remained at approximately $0.73 \mathrm{~mm} / \mathrm{s}$. The vibration spectrum analysis at the inlet pipe and inlet cavity showed that the dominant frequency at the pump inlet was two times the BPF (2BPF), with larger amplitude vibration under the low flow condition. With the increasing flow rate, the dominant frequency of vibration was presented as the BPF, and the amplitude of high frequency was obviously decreased. Thus, the vibration characteristics at the inlet pipe and inlet cavity were mainly affected by the operation conditions.

Figure 5 presents the vibration spectrum at the outlet of the multistage pump of $\mathrm{CH} 7$ and $\mathrm{CH} 8$ under different flow rates, which show the same vibration characteristics as those of $\mathrm{CH} 1$ and $\mathrm{CH} 2$. The vibration was obvious at one time, two times, and three times the BPF. Within the range of 4-8 times the BPF, the vibration amplitude was the most intense, showed multiple peaks, and reduced after eight times the BPF. With the increased flow rate, the vibration amplitude at the outlet section decreased gradually and showed the same variation trend as that observed for the inlet section. The maximum vibration amplitude appeared at the shut-off flow rate point and decreased to the minimum at a high flow rate because the flow in the pump was uneven, with considerable vortexes at the part-loading flow rate. Thus, the vibration characteristics of the monitoring points in the inlet and outlet sections were seriously affected by the operation conditions. These sections were rigid connections in the test system. The test bench might produce secondary frequency vibration due to induction by water flow. Under the high flow condition, the flow in the pump improved, and the vortexes and vibration amplitude were reduced. The vibration characteristics of the inlet and outlet sections were mainly determined by the number of impeller blades, and the domain frequency was the BPF [20].

3.2. Vibration Spectrum Analysis of the Pump Body. The vibration frequency spectra for different flow rates were determined, as shown in Figures 6-8. Three flow conditions (i.e., $0 Q_{\text {des }}, 1.0 Q_{\text {des }}$, and $1.5 Q_{\text {des }}$ ) were analyzed. Each condition exerted a different effect on the vibration amplitude and frequency.

Figure 6 shows the vibration spectrum measured by $\mathrm{CH} 3-\mathrm{CH} 6$ at the shut-off point. The dominant frequencies of the first and last stages were the blade frequency. The secondary frequencies were twice the blade frequency; however, the amplitude of the first stage was significantly higher than that of the last stage. The dominant frequencies of the second- and third-stage pump bodies were two times the blade frequency, and the secondary frequencies were three times the blade frequency. Thus, the amplitudes of the blade frequency and the three times blade frequency were similar in the two stages. At the shut-off point, the peak value was two times the blade frequency of the second stage, which reached $2.82 \mathrm{~mm} / \mathrm{s}$. 


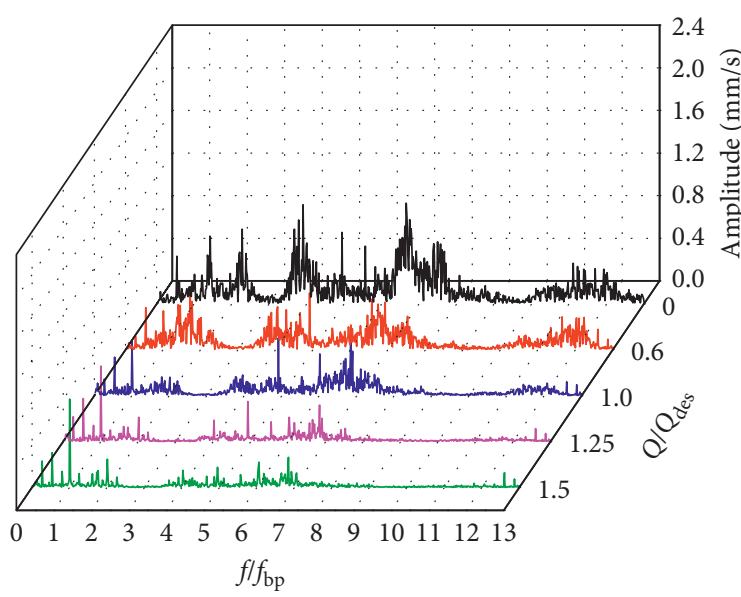

(a)

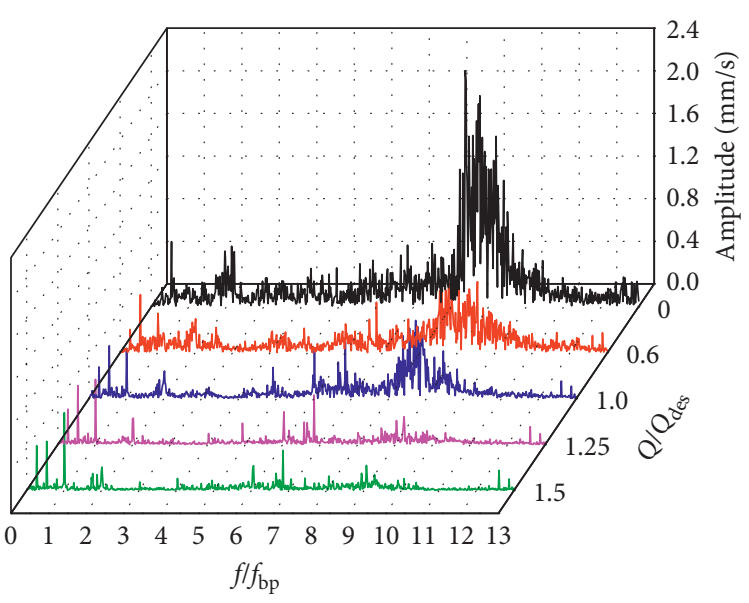

(b)

Figure 4: Vibration frequency spectrum at the pump inlet: (a) $\mathrm{CH} 1$; (b) $\mathrm{CH} 2$.

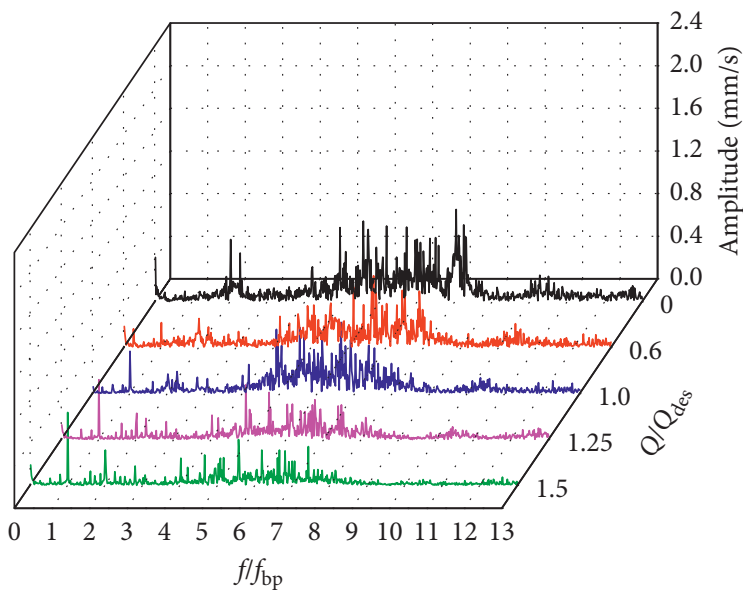

(a)

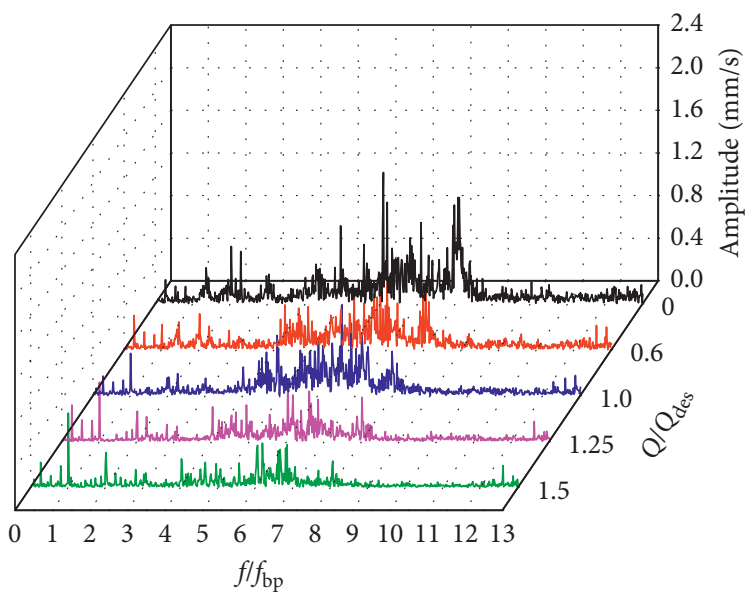

(b)

Figure 5: Vibration frequency spectrum at the pump outlet: (a) CH7; (b) CH8.

The vibration spectra measured by $\mathrm{CH} 3-\mathrm{CH} 6$ under the design flow rate are shown in Figure 7. The dominant frequency of the first-stage pump body was four times the blade frequency. The secondary frequency was three times the blade frequency. The dominant frequency of the secondstage pump body was 2.3 times $(850 \mathrm{~Hz})$ the blade frequency, and the secondary frequency was three times the blade frequency. The vibration amplitude of the third-stage pump body increased significantly compared with the first two stages. The dominant frequency was two times the blade frequency, and the secondary frequency was the blade frequency. In the last stage, the blade frequency was the dominant one, followed by two times the blade frequency. At the design flow rate, the peak value appeared at two times the blade frequency of the third stage and reached $2.24 \mathrm{~mm} / \mathrm{s}$.

With a gradual increase in the flow rate, the vibration spectra were measured by $\mathrm{CH} 3-\mathrm{CH} 6$ at $1.5 Q_{\text {des }}$, as shown in Figure 8. Under the high flow rate, the dominant frequency of the first-stage pump body was four times the blade frequency, and the secondary frequency was three times the blade frequency. The vibration amplitude was similar to that at one and two times the blade frequency. The dominant frequency of the second-stage pump body was $2 \mathrm{BPF}$. The dominant frequencies of the two rear stages were the same as the BPF with similar amplitudes. The peak value appeared at four times the blade frequency of the first-stage pump body and reached $1.99 \mathrm{~mm} / \mathrm{s}$. The peak values and relative harmonics of each monitoring point under varied conditions are summarized in Table 2, and the peak values are shown in bold.

3.3. Vibration among Stages. The analysis of the vibration spectrum at each stage of the pump body under different operation conditions shows that the amplitudes of the dominant frequency at the two extreme conditions (i.e., the shut-off flow rate point $0 Q_{\text {des }}$ and the overloading flow rate $\left.1.5 Q_{\text {des }}\right)$ were considerably higher than that at the design 


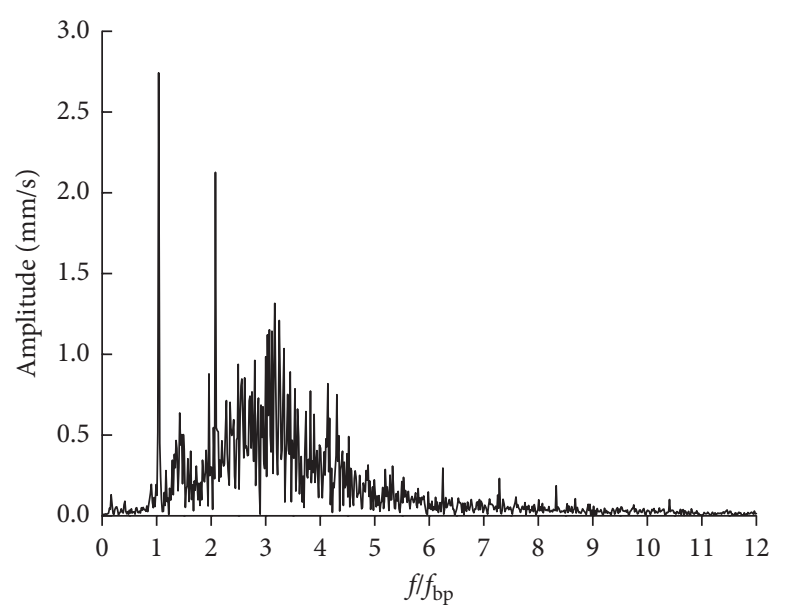

(a)

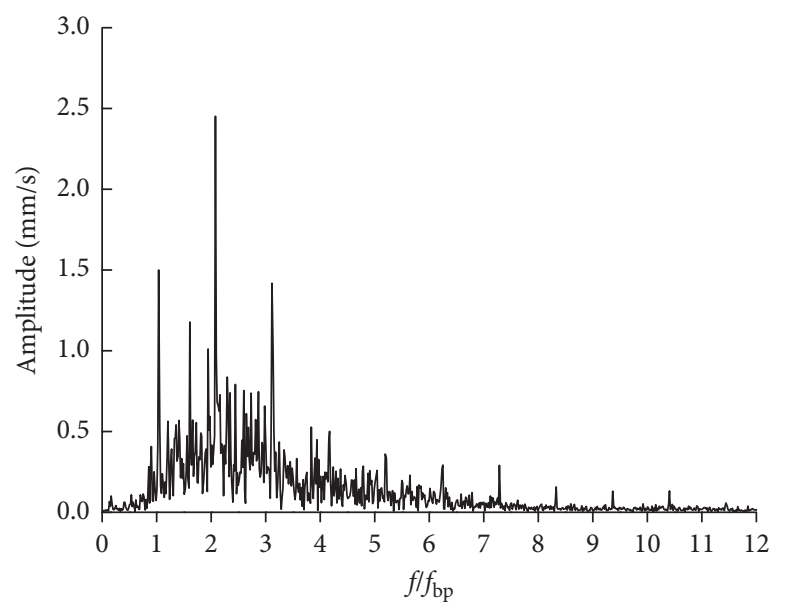

(c)

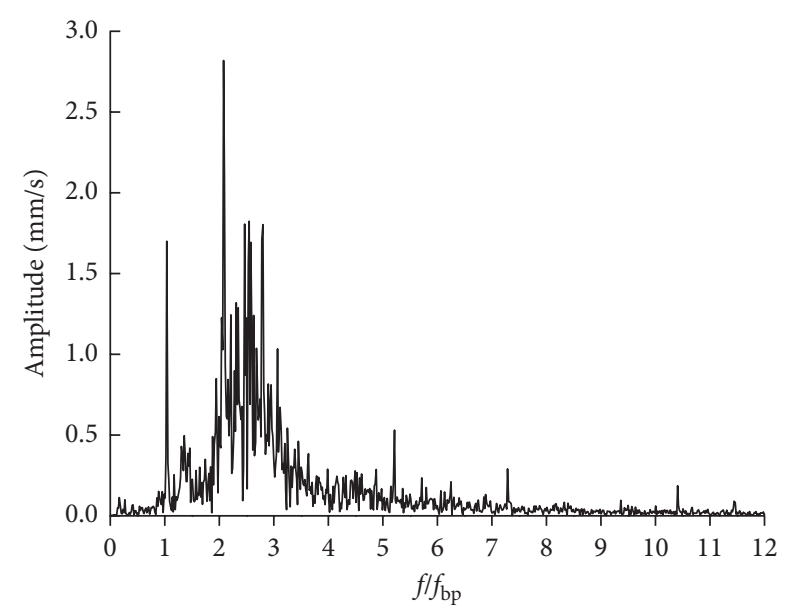

(b)

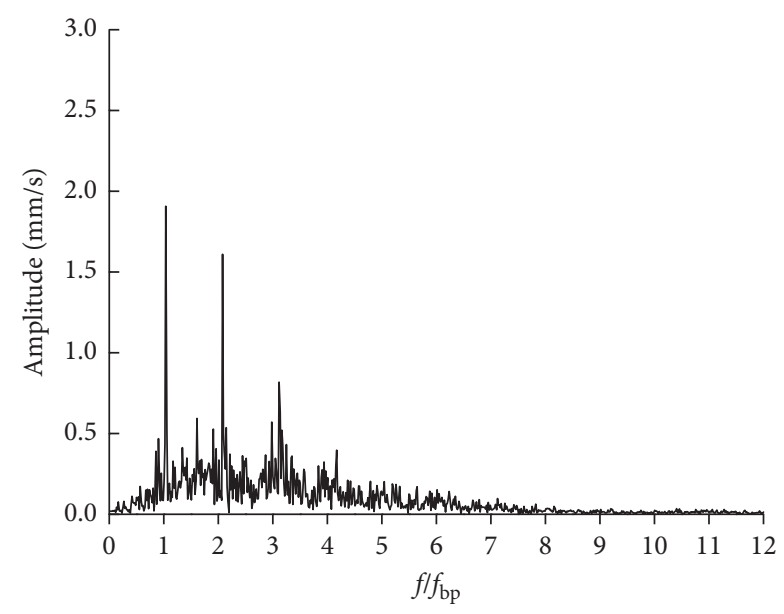

(d)

Figure 6: Vibration spectrum at the zero flow rate: (a) CH3; (b) $\mathrm{CH} 4$; (c) $\mathrm{CH} 5$; (d) $\mathrm{CH} 6$.

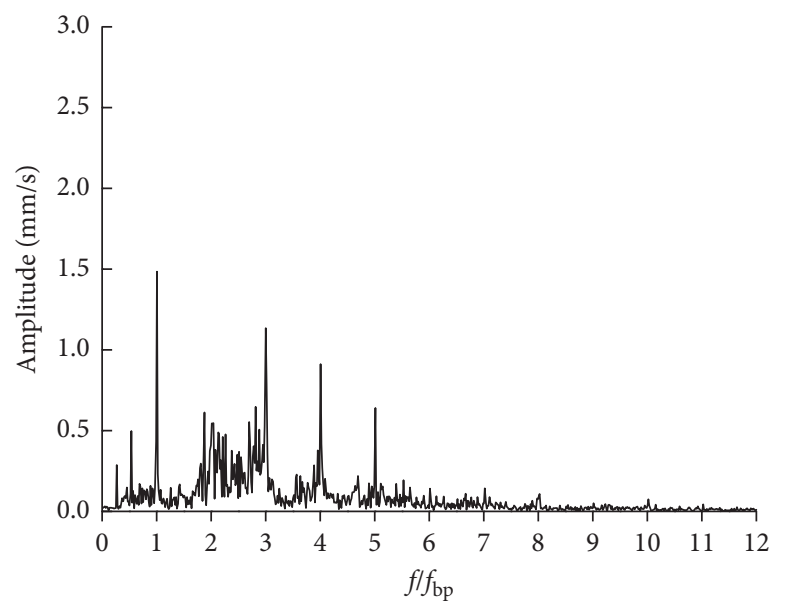

(a)

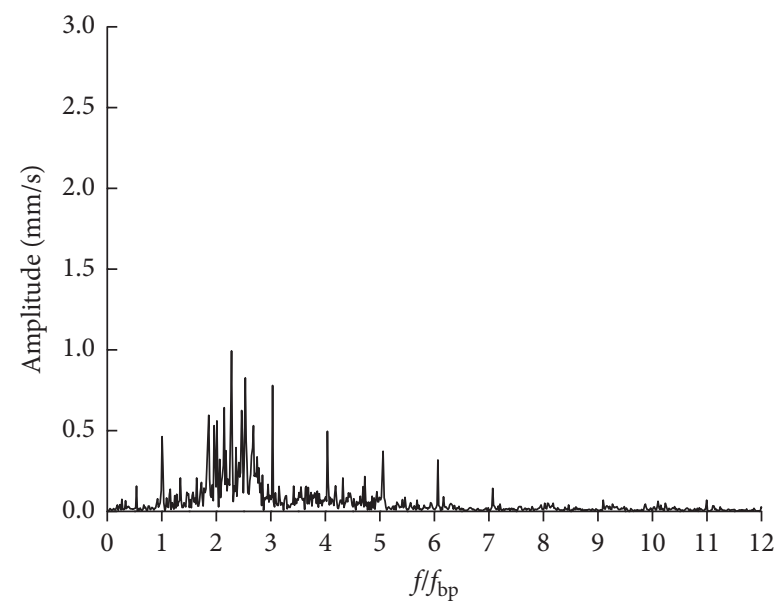

(b)

FIgURE 7: Continued. 


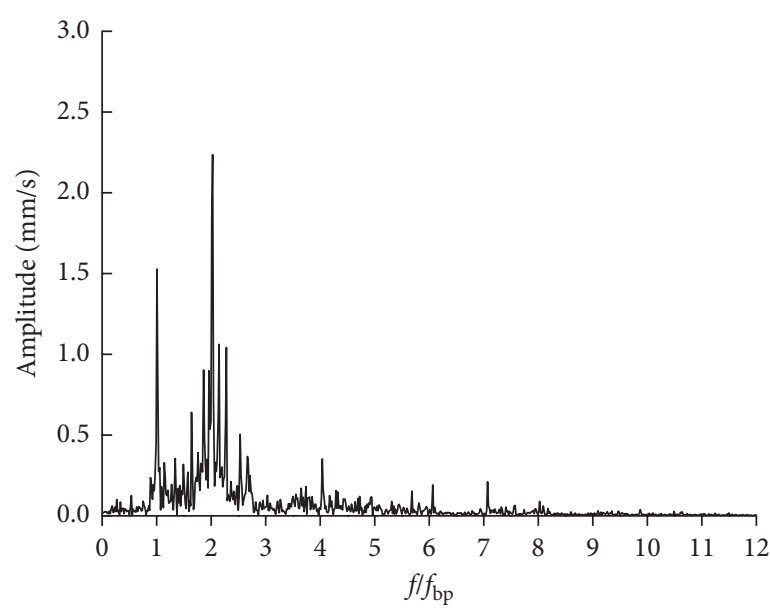

(c)

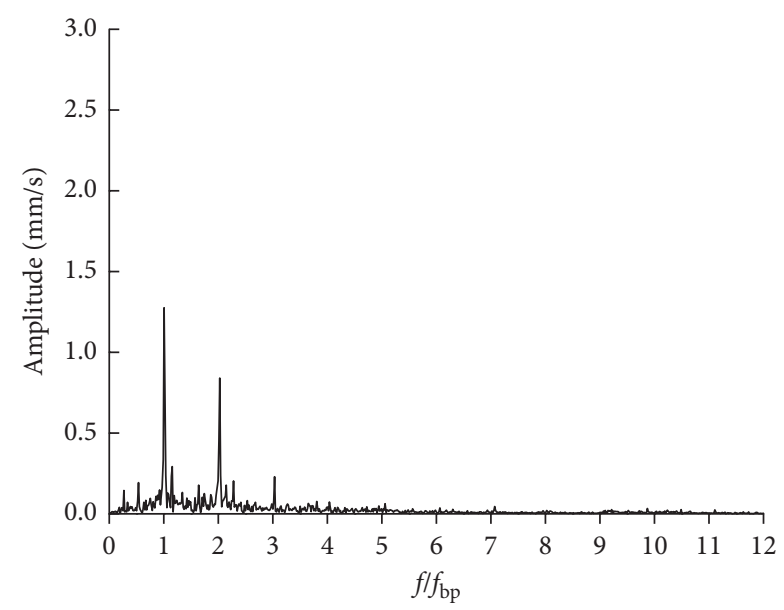

(d)

FIgURE 7: Vibration spectrum at the design flow rate: (a) $\mathrm{CH} 3$; (b) $\mathrm{CH} 4$; (c) $\mathrm{CH} 5$; (d) $\mathrm{CH} 6$.

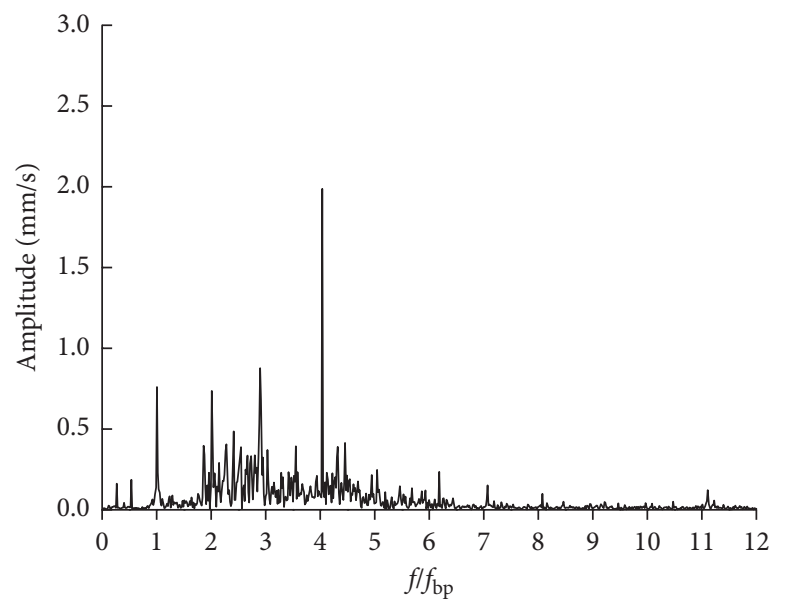

(a)

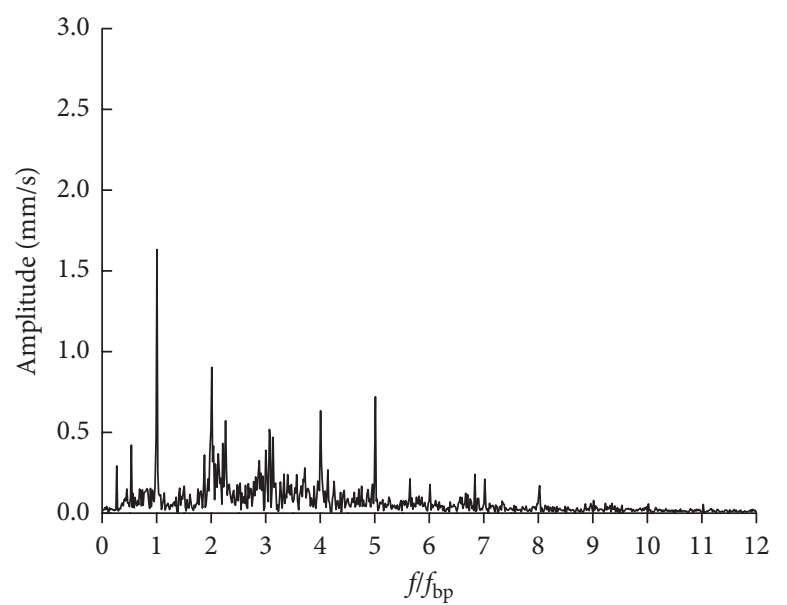

(c)

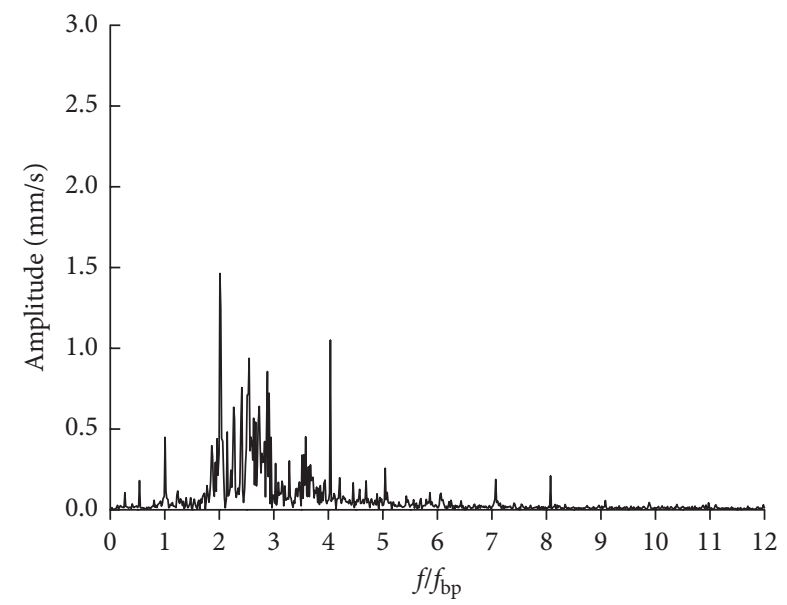

(b)

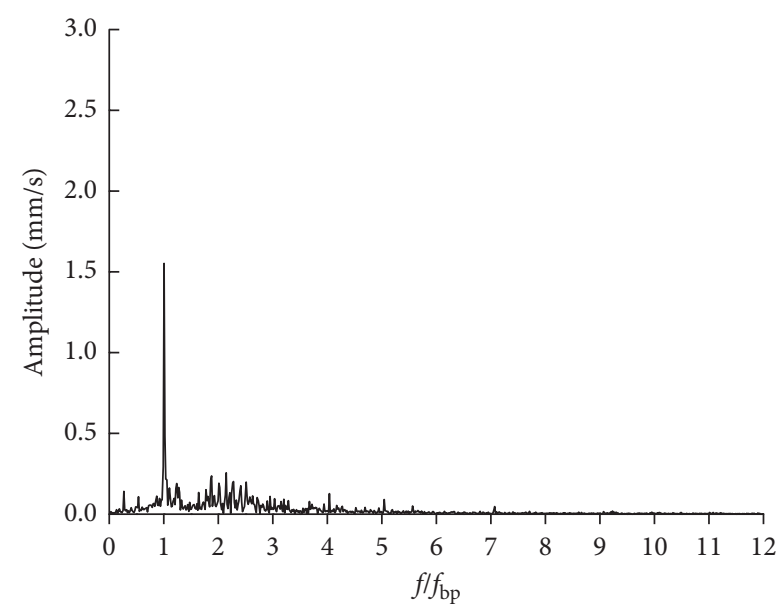

(d)

FIgURE 8: Vibration spectrum at 1.5 times the design flow rate: (a) $\mathrm{CH} 3$; (b) $\mathrm{CH} 4$; (c) $\mathrm{CH} 5$; (d) CH6. 
TABLE 2: Peak value and relative harmonics of each monitoring point under varied conditions.

\begin{tabular}{|c|c|c|c|c|c|}
\hline Channel number & Flow rate & $f / f_{\mathrm{bp}}$ & $2 f / f_{\mathrm{bp}}$ & $3 f / f_{\mathrm{bp}}$ & $4 f / f_{\mathrm{bp}}$ \\
\hline \multirow{3}{*}{$\mathrm{CH} 3$} & $0 Q_{\text {des }}$ & 2.81 & 2.12 & 0.74 & 0.41 \\
\hline & $1.0 Q_{\mathrm{des}}$ & 1.48 & 0.54 & 1.13 & 0.97 \\
\hline & $1.5 Q_{\mathrm{des}}$ & 0.76 & 0.74 & 0.88 & 1.99 \\
\hline \multirow{3}{*}{$\mathrm{CH} 4$} & $0 Q_{\mathrm{des}}$ & 1.64 & 2.85 & 1.01 & 0.30 \\
\hline & $1.0 Q_{\mathrm{des}}$ & 0.46 & 0.56 & 0.78 & 0.49 \\
\hline & $1.5 Q_{\mathrm{des}}$ & 0.45 & 1.46 & 0.72 & 1.05 \\
\hline \multirow{3}{*}{$\mathrm{CH} 5$} & $0 Q_{\mathrm{des}}$ & 1.51 & 2.47 & 1.45 & 0.48 \\
\hline & $1.0 Q_{\mathrm{des}}$ & 1.53 & 2.24 & 0.13 & 0.35 \\
\hline & $1.5 Q_{\mathrm{des}}$ & 1.63 & 0.90 & 0.49 & 0.63 \\
\hline \multirow{3}{*}{$\mathrm{CH} 6$} & $0 Q_{\mathrm{des}}$ & 1.89 & 1.61 & 0.82 & 0.47 \\
\hline & $1.0 Q_{\mathrm{des}}$ & 1.28 & 0.84 & 0.30 & 0.09 \\
\hline & $1.5 Q_{\text {des }}$ & 1.55 & 0.19 & 0.11 & 0.06 \\
\hline
\end{tabular}

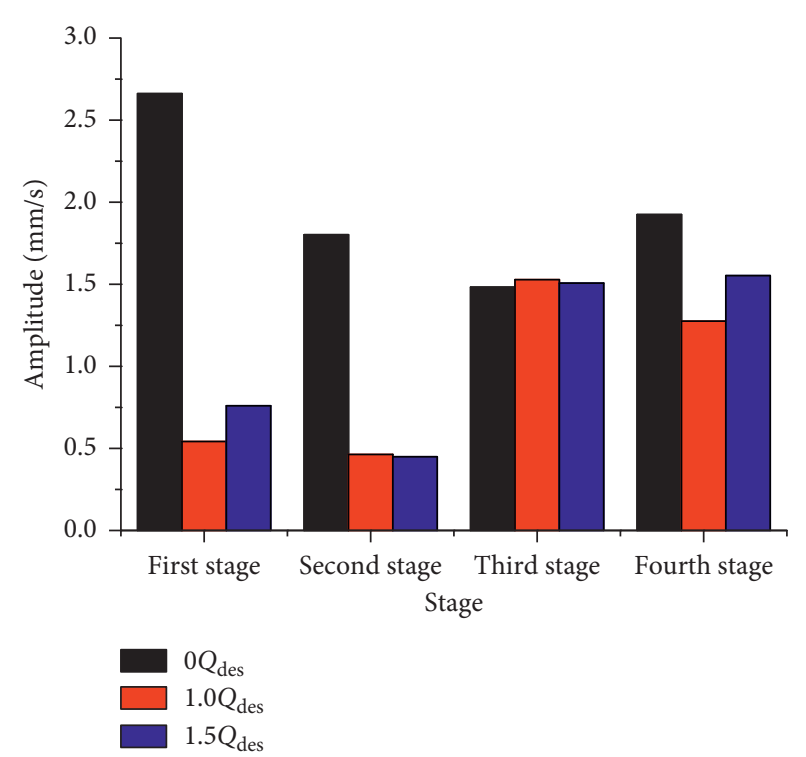

(a)

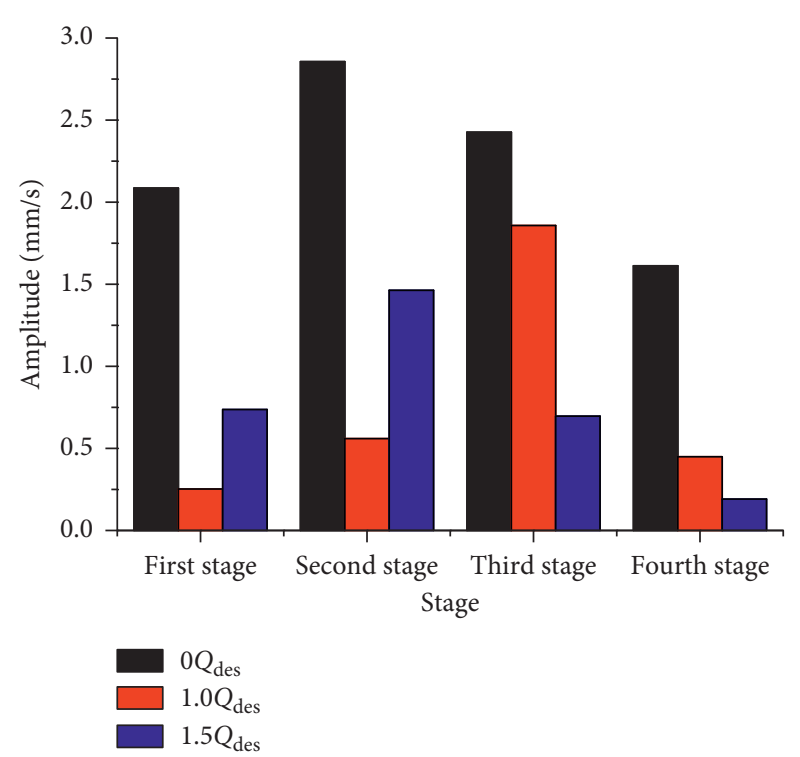

(b)

FIGURE 9: Vibration on each stage under (a) BPF and (b) 2BPF.

flow rate for the first-stage pump body. These deviations from the design conditions caused differences in the fluid exciting force, flow, radial force, and axial force during the multistage pump operation. The vibration dominant frequency at the shut-off point was the same as the BPF but was four times the BPF at the other two flow rates. The amplitude of the dominant frequency was lowest at the design flow rate. For the second stage, the vibration at the shut-off flow rate point was similar to that at the high flow rate. Both dominant frequencies appeared at two times the BPF; however, the amplitude of the dominant frequency at the shut-off flow rate point was $0.45 \mathrm{~mm} / \mathrm{s}$ higher than that at the high flow rate. The vibration characteristics of the third stage changed distinctly with the flow rate, which primarily suggested that the amplitude decreased with increased flow rates, and the dominant frequency was reduced to the $\mathrm{BPF}$ from $2 \mathrm{BPF}$. The last-stage pump body was connected with the outlet cover. All dominant frequencies were the same as the blade frequency under different conditions, and the amplitude was the smallest at the design flow rate. From the spectrum of the vibration characteristics, the vibration was mainly concentrated in the low-frequency area, from one to four times the BPF. This result indicated that the pressure pulsation produced by the rotor-stator interaction was an important source of vibration in the cantilever centrifugal pump.

The variation diagrams for $\mathrm{BPF}$ and $2 \mathrm{BPF}$ at the monitoring points of each stage of the pump body are plotted in Figure 9 to analyze the variation in the main vibration frequency with the operation conditions. At the shut-off flow rate point, the amplitudes of the vibration velocity at the BPF initially decreased and then increased from the first to the last stage. Meanwhile, the amplitudes at 2BPF initially increased and then decreased. Under the design flow or the high flow conditions, the amplitudes at the BPF gradually increased from the first to the last stage, which indicated that the pressure in the pump increased with the stages during pump operation. The vibration produced by the pressure fluctuation was greater than that caused by the mass unbalance of the cantilever. 


\section{Conclusion}

The vibration state of a cantilever multistage centrifugal pump has been measured and analyzed for different flow rates in this study. The results showed that the flow rates exerted distinct effects on the vibration spectrum at the inlet and outlet sections of the cantilever multistage centrifugal pump. The amplitudes of the vibration velocity were larger under the extreme flow conditions (i.e., $0 Q_{\mathrm{des}}$ and $1.5 Q_{\mathrm{des}}$ ). The dominant frequencies at different stages could change with the operation conditions. The dominant frequency for the first and last stages was the BPF at the shut-off flow rate point, and the dominant frequency of other stages was 2BPF. The variation in the vibration dominant frequency at the overloading flow rates was similar to that at the design flow rate. The dominant frequency of the last-stage pump body was the BPF under different flow rate conditions because the last-stage diffuser vanes were connected with the outlet section. The main vibration frequency range of the cantilever multistage centrifugal pump was found to be in the range of one to four times the BPF and likely to be one or two times the blade frequency. Mass unbalance primarily accounted for the vibration at the shut-off flow rate point. However, pump vibration was mainly caused by the pressure pulsation at the design and overloading flow rates.

The presented results could enrich the known database for optimization purposes. The domain frequency relates to the $\mathrm{BPF}$, and the vibration frequency concentrates at the low-frequency range; hence, the vibration by the arrangement of impeller blades among stages can be reduced or controlled. The whole study confirms the validity and potential for future research works on the topic of the stage coupling vibration.

\section{Nomenclature}

$\begin{array}{ll}Q_{\text {des }}: & \text { Design flow rate }\left(\mathrm{m}^{3} / \mathrm{h}\right) \\ H_{\mathrm{s}}: & \text { Single-stage head }(\mathrm{m}) \\ n: & \text { Rotation speed }(\mathrm{r} / \mathrm{min}) \\ z_{\mathrm{i}}: & \text { The number of impeller blades } \\ z_{\mathrm{d}}: & \text { The number of diffuser vanes } \\ f_{\mathrm{bp}}: & \text { Blade passing frequency }(\mathrm{Hz}) \\ f_{\mathrm{s}}: & \text { Shaft frequency }(\mathrm{Hz}) \\ \mathrm{BPF}: & \text { Blade passing frequency. }\end{array}$

\section{Data Availability}

The experimental data used to support the findings of this study are included within the article.

\section{Conflicts of Interest}

The authors declare that there are no conflicts of interest regarding the publication of this paper.

\section{Acknowledgments}

The work was supported by the National Natural Science Foundation of China (Grant no. 51609106), China Postdoctoral Science Foundation (Grant nos. 2015M581737 and
2017T100331), and the Funding for the Construction of Dominant Disciplines in Colleges and Universities in Jiangsu (PAPD).

\section{References}

[1] Y. Wu, S. Li, S. Liu et al., Vibration of Hydraulic Machinery, Springer, Berlin, Germany, 2013.

[2] M. Milovančević, V. Nikolić, D. Petkovic et al., "Vibration analyzing in horizontal pumping aggregate by soft computing," Measurement, vol. 125, pp. 454-462, 2018.

[3] Z. Lu, C. Wang, N. Qiu et al., "Experimental study on the unsteady performance of the multistage centrifugal pump," Journal of the Brazilian Society of Mechanical Sciences and Engineering, vol. 40, no. 5, pp. 1-10, 2018.

[4] C. Wang, X. Chen, N. Qiu et al., "Numerical and experimental study on the pressure fluctuation, vibration, and noise of multistage pump with radial diffuser," Journal of the Brazilian Society of Mechanical Sciences and Engineering, vol. 40, no. 10, p. 481, 2018.

[5] C. Wang, W. Shi, X. Wang et al., "Optimal design of multistage centrifugal pump based on the combined energy loss model and computational fluid dynamics," Applied Energy, vol. 187, pp. 10-26, 2017.

[6] W. Li, X. Jiang, Q. Pang et al., "Numerical simulation and performance analysis of a four-stage centrifugal pump," Advances in Mechanical Engineering, vol. 8, no. 10, pp. 1-8, 2016.

[7] S. Zhang, X. Li, and Z. Zhu, "Numerical simulation of cryogenic cavitating flow by an extended transport-based cavitation model with thermal effects," Cryogenics, vol. 92, pp. 98-104, 2018.

[8] X. Li, P. Gao, Z. Zhu, and Y. Li, "Effect of the blade loading distribution on hydrodynamic performance of a centrifugal pump with cylindrical blades," Journal of Mechanical Science and Technology, vol. 32, no. 3, pp. 1161-1170, 2018.

[9] H. Zhou, Y. Mao, Q. Diao, F. A. Lu, and Q. Zhang, "Numerical analysis of the vibration and noise induced by the unsteady flow in a centrifugal compressor," Proceedings of the Institution of Mechanical Engineers, Part A: Journal of Power and Energy, vol. 230, no. 6, pp. 554-569, 2016.

[10] A. E. Khalifa, "Effect of blade exit shape on performance and vibration of a double volute centrifugal pump," International Journal of Materials Mechanics \& Manufacturing, vol. 2, no. 4, pp. 261-264, 2014.

[11] J. Grosel, W. Pakos, and W. Sawicki, "Experimental measurements as the basis for determination of the source of pumps' excessive vibration," Procedia Engineering, vol. 111, pp. 269-276, 2015.

[12] J. Yang, G. Pavesi, X. Liu, T. Xie, and J. Liu, "Unsteady flow characteristics regarding hump instability in the first stage of a multistage pump-turbine in pump mode," Renewable Energy, vol. 127, pp. 377-385, 2018.

[13] M. A. S. Al Tobi, G. Bevan, K. P. Ramachandran et al., "Experimental set-up for investigation of fault diagnosis of a centrifugal pump. World Academy of Science, Engineering and Technology," International Journal of Mechanical, Aerospace, Industrial, Mechatronic and Manufacturing Engineering, vol. 11, no. 3, pp. 481-485, 2017.

[14] V. Muralidharan, V. Sugumaran, and V. Indira, "Fault diagnosis of monoblock centrifugal pump using SVM," Engineering Science and Technology, an International Journal, vol. 17, no. 3, pp. 152-157, 2014. 
[15] A. Adamkowski, A. Henke, and M. Lewandowski, "Resonance of torsional vibrations of centrifugal pump shafts due to cavitation erosion of pump impellers," Engineering Failure Analysis, vol. 70, pp. 56-72, 2016.

[16] S. Wu, Y. Zhang, and P. Zhang, "Simulation on performance of a centrifugal pump during rapid startup period," Journal of Drainage and Irrigation Machinery Engineering, vol. 36, no. 6, pp. 467-471, 2018.

[17] L. Zhou, L. Bai, W. Li, W. Shi, and C. Wang, "PIV validation of different turbulence models used for numerical simulation of a centrifugal pump diffuser," Engineering Computations, vol. 35, no. 1, pp. 2-17, 2018.

[18] J. Gonzalez, J. Fernández, E. Blanco et al., "Numerical simulation of the dynamic effects due to impeller-volute interaction in a centrifugal pump," Journal of Fluids Engineering, vol. 124, no. 2, pp. 348-355, 2002.

[19] T. Schäfer, A. Bieberle, M. Neumann, and U. Hampel, "Application of gamma-ray computed tomography for the analysis of gas holdup distributions in centrifugal pumps," Flow Measurement and Instrumentation, vol. 46, pp. 262-267, 2015.

[20] H. Chen, T. Zhang, and C. Wang, "Structural characteristics of ultrahigh-pressure multistage centrifugal pump typed SDZ310," Journal of Drainage and Irrigation Machinery Engineering, vol. 36, no. 7, pp. 567-572, 2018. 


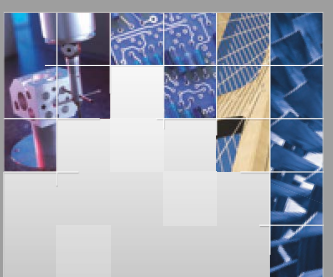

\section{Enfincering}
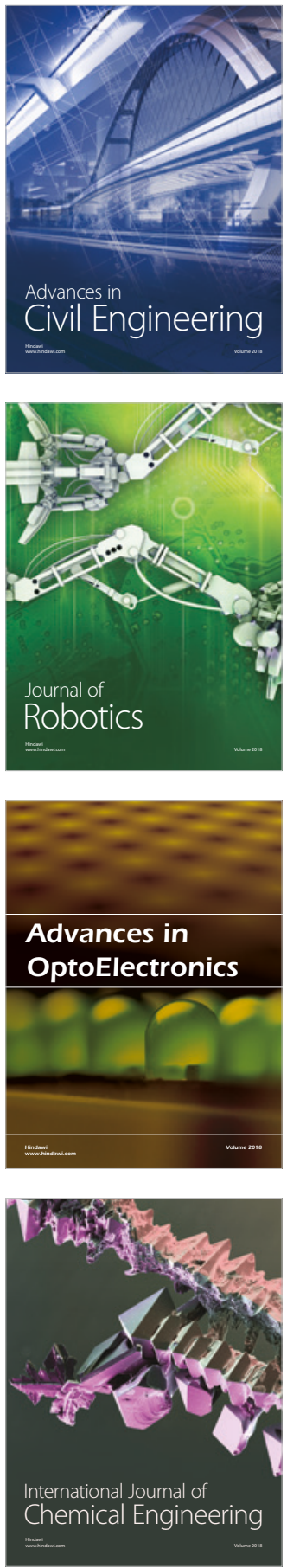

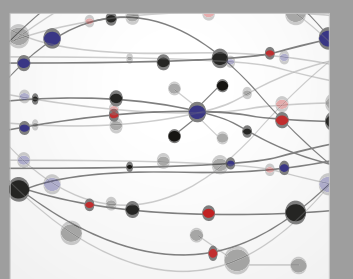

\section{Rotating \\ Machinery}

The Scientific World Journal

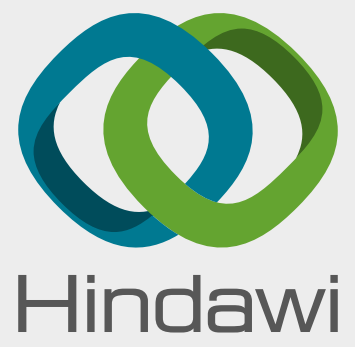

Submit your manuscripts at

www.hindawi.com
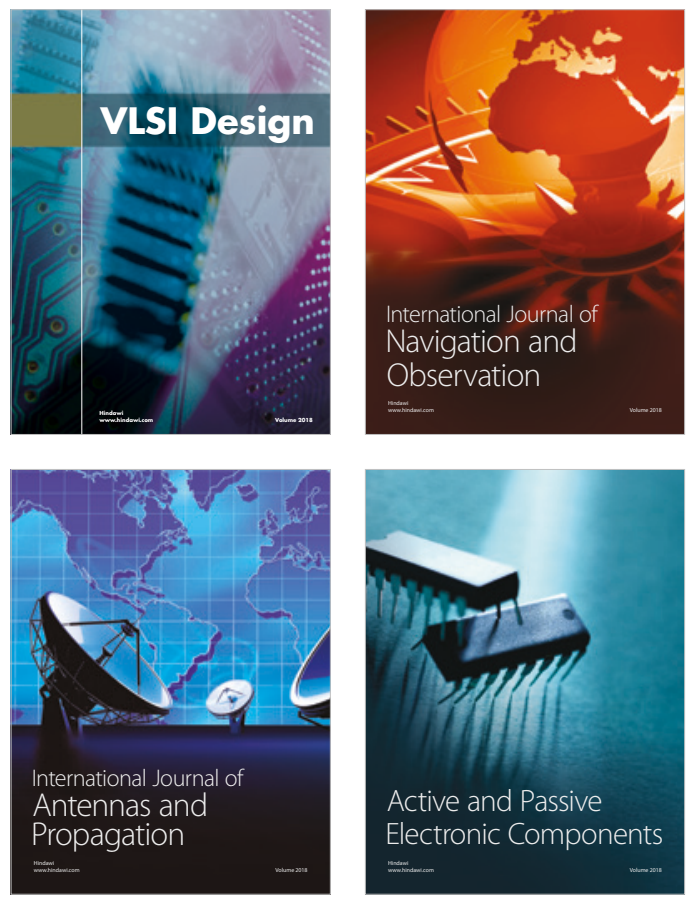
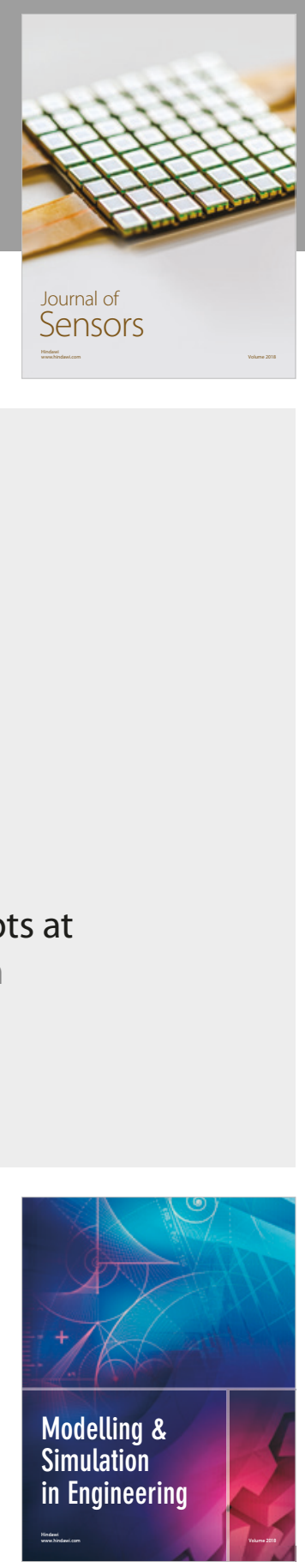

\section{Advances \\ Multimedia}
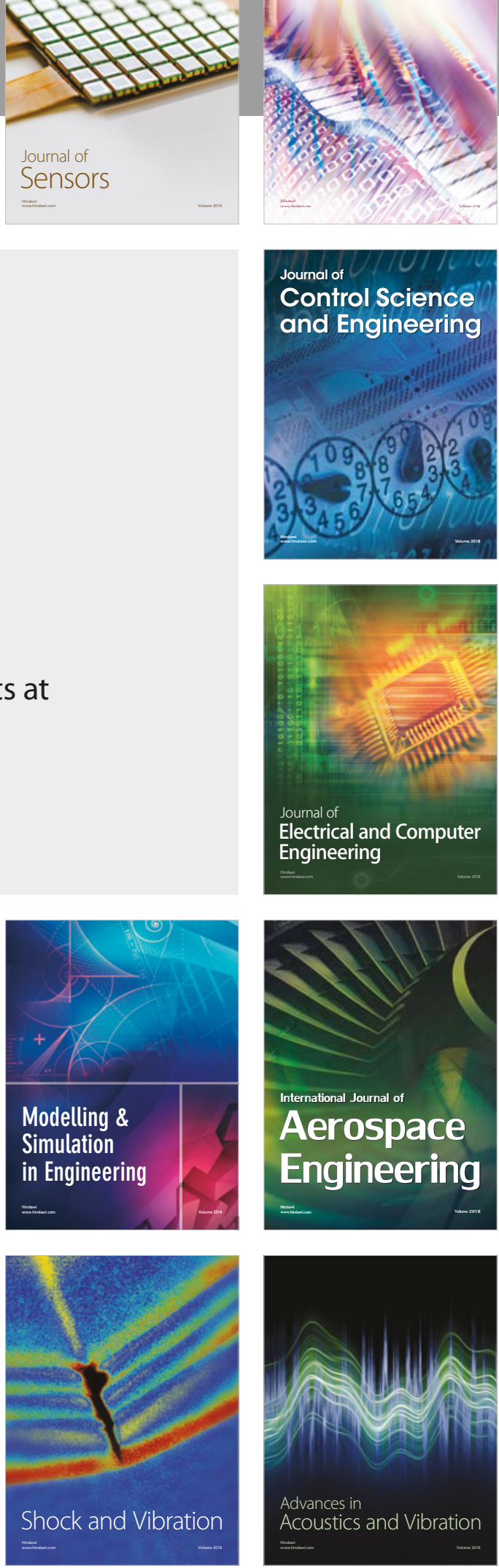